\title{
A spectrophotometric study on uranyl nitrate complexation to $150^{\circ} \mathrm{C}$
}

\section{Journal Article}

\section{Author(s):}

Suleimenov, O. M.; Seward, Terry M.; Hovey, J. K.

Publication date:

2007

Permanent link:

https://doi.org/10.3929/ethz-b-000007720

Rights / license:

In Copyright - Non-Commercial Use Permitted

Originally published in:

Journal of solution chemistry 36(9), https://doi.org/10.1007/s10953-007-9175-9 


\title{
A Spectrophotometric Study on Uranyl Nitrate Complexation to $150{ }^{\circ} \mathrm{C}$
}

\author{
O.M. Suleimenov • T.M. Seward • J.K. Hovey
}

Received: 19 December 2006 / Accepted: 9 March 2007 / Published online: 26 July 2007

(C) Springer Science+Business Media, LLC 2007

\begin{abstract}
The formation constant of the mononitratouranyl complex was studied spectrophotometrically at temperatures of $25,40,55,70,100$ and $150^{\circ} \mathrm{C}(298,313,328,343$, 373 and $423 \mathrm{~K}$ ). The uranyl ion concentration was fixed at approximately $0.008 \mathrm{~mol} \cdot \mathrm{kg}^{-1}$ and the ligand concentration was varied from 0.05 to $3.14 \mathrm{~mol} \cdot \mathrm{kg}^{-1}$. The uranyl nitrate complex, $\mathrm{UO}_{2} \mathrm{NO}_{3}^{+}$, is weak at $298 \mathrm{~K}$ but its equilibrium constant (at zero ionic strength) increases with temperature from $\log _{10} \beta_{1}=-0.19 \pm 0.02(298 \mathrm{~K})$ to $0.78 \pm 0.04(423 \mathrm{~K})$.
\end{abstract}

Keywords Stability constants $\cdot$ Uranyl nitrate $\cdot$ Spectrophotometric $\cdot$ Aqueous solution

\section{Introduction}

Uranyl ion and its complexes with various ligands plays an important role in the extraction and beneficiation chemistry of uranium. Quantitative modeling of these processes as well as the modeling of the other chemical, geological and biological processes involving uranium requires knowledge of reliable thermodynamic complexation constants. Recently, the study of uranyl complexes with inorganic ligands such as $\mathrm{Cl}^{-}, \mathrm{CO}_{3}^{2-}, \mathrm{SO}_{4}^{2-}$ and $\mathrm{NO}_{3}^{-}$ in aqueous solutions at elevated temperatures has undergone renewed interest because of the importance of uranium solution chemistry and mobility in nuclear waste disposal environments. Available literature data on uranyl complexation constants with nitrate ion suffer from inconsistency and are limited to only low temperature ambient conditions.

The interaction between $\mathrm{UO}_{2}^{2+}$ and $\mathrm{NO}_{3}^{-}$is weak, with reported values for the apparent equilibrium constant for $\mathrm{UO}_{2} \mathrm{NO}_{3}^{+}$formation [1-9] ranging from 0.04 to 0.63 at $25^{\circ} \mathrm{C}$ (Table 1 , Refs. $[2,3,5,8])$. The large scatter reflects the difficulty in determining the stability of weak complexes, often with inappropriate methods. Of particular interest is the study by Brooker et al. [9] whose Raman spectroscopic measurements of uranyl nitrate complexion in aqueous nitrate media provide evidence for the formation of only one complex, $\mathrm{UO}_{2} \mathrm{NO}_{3}^{+}$,

O.M. Suleimenov $(\bowtie) \cdot$ T.M. Seward · J.K. Hovey

Institut für Mineralogie und Petrographie, Eidgenössische Technische Hochschule (ETH),

CH-8092 Zürich, Switzerland

e-mail: oleg@erdw.ethz.ch 
Table 1 Thermodynamic data for the reaction $\mathrm{UO}_{2}^{2+}(\mathrm{aq})+\mathrm{NO}_{3}^{-}(\mathrm{aq}) \rightleftarrows \mathrm{UO}_{2} \mathrm{NO}_{3}^{+}(\mathrm{aq})$ where $Q$ is the apparent equilibrium constant

\begin{tabular}{|c|c|c|c|c|}
\hline$t /{ }^{\circ} \mathrm{C}$ & Medium $^{\mathrm{a}}$ & $Q$ & Method $^{\mathrm{b}}$ & Reference \\
\hline 20 & $1 M \mathrm{NaClO}_{4}$ & 0.50 & Emf & Ahrland [1] \\
\hline 25 & $\begin{array}{l}5.38 M\left(\mathrm{Na}^{+}, \mathrm{H}^{+}\right)\left(\mathrm{ClO}_{4}^{-}, \mathrm{NO}_{3}^{-}\right) \\
7.0 M\left(\mathrm{Na}^{+}, \mathrm{H}^{+}\right)\left(\mathrm{ClO}_{4}^{-}, \mathrm{NO}_{3}^{-}\right)\end{array}$ & $\begin{array}{l}0.21 \\
0.27\end{array}$ & spec & Betts and Michels [2] \\
\hline $\begin{array}{l}10 \\
25 \\
40\end{array}$ & $2 \mathrm{M} \mathrm{NaClO}_{4}$ & $\begin{array}{l}0.30 \\
0.24 \\
0.17\end{array}$ & dist & Day and Powers [3] \\
\hline 32 & $1 M \mathrm{NaClO}_{4}$ & 0.04 & exch & Banerjee and Tripathi [4] \\
\hline 25 & $\begin{array}{l}0.54 M\left(\mathrm{Na}^{+}, \mathrm{H}^{+}\right)\left(\mathrm{ClO}_{4}^{-}, \mathrm{NO}_{3}^{-}\right) \\
0.82 M\left(\mathrm{Na}^{+}, \mathrm{H}^{+}\right)\left(\mathrm{ClO}_{4}^{-}, \mathrm{NO}_{3}^{-}\right) \\
1.06 \mathrm{M}\left(\mathrm{Na}^{+}, \mathrm{H}^{+}\right)\left(\mathrm{ClO}_{4}^{-}, \mathrm{NO}_{3}^{-}\right)\end{array}$ & $\begin{array}{l}0.37 \\
0.20 \\
0.19\end{array}$ & Emf & Ohashi and Morozumi [5] \\
\hline 20 & $8 \mathrm{M} \mathrm{HClO}_{4}$ & 2.94 & dist & Lahr and Knock [6] \\
\hline 22 & $\begin{array}{l}0 M\left(\mathrm{NaClO}_{4}\right) \\
2 M\left(\mathrm{NaClO}_{4}\right)\end{array}$ & $\begin{array}{l}0.25 \\
0.29\end{array}$ & spec & Marcantonatos et al. [7] \\
\hline 25 & $0.71 \mathrm{M} \mathrm{HClO}_{4}$ & 0.63 & dist & Pushlenkov et al. [8] \\
\hline 23 & $6.25 M\left(\mathrm{Na}^{+}, \mathrm{H}^{+}\right)\left(\mathrm{ClO}_{4}^{-}, \mathrm{NO}_{3}^{-}\right)$ & 0.15 & spec & Brooker et al. [9] \\
\hline 30 & $3 M \mathrm{HNO}_{3}$ & 0.33 & Emf & Guorong et al. [22] \\
\hline
\end{tabular}

${ }^{\mathrm{a}} M$ denotes units of $\mathrm{mol} \cdot \mathrm{L}^{-1}$

${ }^{b}$ Abbreviations used are: Emf, potentiometric; spec, spectroscopic; dist, liquid-liquid distribution (water/ organic phase); exch, ion exchange

over the entire ligand concentration range to $6.25 \mathrm{~mol} \cdot \mathrm{kg}^{-1}$. The aim of this study has, therefore, been to study the formation of the mononitratouranyl complex over a wider range of temperature from 25 to $150^{\circ} \mathrm{C}$ at pressures from 1 to 4 bar.

\section{Experimental Part}

The water used for all experiments was first passed through a Milli-Q reagent grade mixedbed ion-exchange column and then double distilled in quartz glass. The resistivity of the water was $18.2 \mathrm{M} \Omega \cdot \mathrm{cm}$. Nitric acid was used without further purification. Uranyl nitrate hexahydrate (Fishers 99\%) was purified by slow recrystallization from dilute solutions of nitric acid. An approximately $0.05 \mathrm{~mol} \cdot \mathrm{kg}^{-1}$ uranyl nitrate stock solution was prepared by adding the purified salt to nitric acid. The uranium concentration in the stock solution was determined gravimetrically using 8-hydroxyquinoline as described by Vogel [10]. Thirteen solutions were prepared by quantitative dilution of the uranium containing stock solution with nitric acid. The uranyl concentration after dilution was approximately $0.008 \mathrm{~mol} \cdot \mathrm{kg}^{-1}$ and the ligand concentrations were varied from 0.05 to $3.14 \mathrm{~mol} \cdot \mathrm{kg}^{-1}$. The total anion concentration (i.e., $\mathrm{NO}_{3}^{-}$) in the working solutions was determined by passing weighed aliquots of the solutions through an ion-exchange resin and titrating the eluents with a standard solution of sodium hydroxide.

The UV-Vis spectra were measured at various temperatures with a double beam Cary 5 UV-Vis spectrophotometer in a thermostatted flow-through fused silica cuvette (Hellma AG) with a $1 \mathrm{~cm}$ optical path. Digital spectra were obtained at $0.2 \mathrm{~nm}$ intervals with a slit width 
of $1 \mathrm{~nm}$. Temperatures were controlled to $\pm 0.005^{\circ} \mathrm{C}$ with separate Sodev CT-L circulating baths and monitored with calibrated thermistors. At 100 and $150^{\circ} \mathrm{C}$, a slight overpressure of nitrogen gas was applied by means of a titanium separator with a movable piston in order to prevent boiling of the solutions.

\section{Computational Method}

The digital spectra recorded for different wavelengths and different solutions can be represented by an $m \times n$ matrix, A, where $m$ is the number of data points (i.e., absorbance at specific wavelengths) and $n$ is the number of solutions. Assuming the validity of Beer's law, we can write

$$
\mathbf{A}=l \varepsilon \mathbf{C}
$$

where $l$ is an optical path length $(1 \mathrm{~cm}), \boldsymbol{\varepsilon}$ is the $m \times j$ matrix of molar absorptivities, $\mathbf{C}$ is the $j \times n$ matrix of concentrations on the molar scale, and $j$ is number of the absorbing species in solution. At this point, generally speaking, we do not know either $\boldsymbol{\varepsilon}$ or $\mathbf{C}$. If the chemical model for the processes taking place in the system is known, we can calculate the matrix of concentrations by solving mass action and mass balance equations and then obtain molar absorptivities for the individual absorbing species that are columns of the matrix $\boldsymbol{\varepsilon}$. On the other hand, any real rectangular matrix can be represented by the following relation using singular value decomposition (SVD) [11]

$$
\mathbf{A}=\mathbf{U D V}^{T}
$$

where $\mathbf{U}(m \times n)$ and $\mathbf{V}(n \times n)$ are matrices with orthogonal columns and $\mathbf{D}$ is the diagonal matrix of singular values. SVD is a widely used technique in statistics, image and signal processing, and pattern recognition. The SVD provides not only a numerically robust solution to the least-squares problem, but it is also directly related to the principle component analysis [12]. Applying principal components analysis (PCA) to the absorbance matrix, A, we choose a new coordinate system for the data set such that the greatest variance by any projection of the data set lies on the first axis (then called the first principal component), the second greatest variance on the second axis, and so on. The singular values can be used to determine the effective rank of a matrix, $\mathbf{A}$, and hence the number of absorbing species in the system necessary for the construction of the chemical model. This is facilitated using the Factor Indication Function (IND) [13],

$$
\mathrm{IND}=\frac{\operatorname{RSD}(k)}{(n-k)^{2}}
$$

where $\operatorname{RSD}(k)$ is the Residual Standard Deviation [14] calculated from the misfit of the product $\mathbf{U}_{m \times r} \mathbf{D}_{r \times r} \mathbf{V}_{n \times r}^{T}$ for any first $r$ vectors to the raw absorbance data. The inverse of this function typically reaches a sharp maximum at the optimal value of $r$, thus indicating the number of absorbing species in the system. If we focus only on these $r$ significant singular values, we can represent the absorbance matrix, $\mathbf{A}$, in the form,

$$
\mathbf{A}=\mathbf{U D V}^{T}+\mathbf{E}
$$

where the diagonal matrix, $\mathbf{D}$ has now the $r \times r$ dimension and the matrix $\mathbf{E}$ contains experimental noise. The advantage of the SVD lies in the decreasing dimensionality of the 
original vector space and the filtering out of the random noise. Combining Eqs. 1 and 4 and discarding the random noise term, we can write

$$
\mathbf{U D V}^{T}=l \varepsilon \mathbf{C} .
$$

By introducing the square rotation matrix, $\mathbf{R}(r \times r)$, we can relate the abstract orthogonal matrices, $\mathbf{U}$ and $\mathbf{V}$, to the desired matrix of absorptivity and the matrix of concentrations as follows:

$$
\mathbf{U D R R}^{-1} \mathbf{V}^{T}=l \varepsilon \mathbf{C}
$$

and hence

$$
\begin{aligned}
& \mathbf{U D R}=l \boldsymbol{\varepsilon} \\
& \mathbf{R}^{-1} \mathbf{V}^{T}=\mathbf{C} .
\end{aligned}
$$

The latter over-determined system of linear equations can be solved in a linear least-squares sense, providing knowledge of the concentration matrix, which is in turn determined by equilibrium constants defined by the chemical model. The formation constants for each temperature were optimized with this approach by minimizing the reduced $\chi^{2}$ (Bevington and Robinson [15]) of $\left|\mathbf{U}_{m \times r} \mathbf{D}_{r \times r} \mathbf{V}_{n \times r}^{T}-\boldsymbol{\varepsilon} \mathbf{C}\right|$ of all the spectrophotometric measurements by the Levenberg-Marquardt technique [16]. Once optimum values for $\mathbf{R}$ are known, the calculation of the molar absorptivity matrix, $\boldsymbol{\varepsilon}$, is straightforward according to Eq. 7a. Standard deviations were then estimated using the method of the parabolic expansion of $\chi^{2}$ about the minima using the numerical second derivatives (e.g., Ref. [15]). All calculations were carried out in the computational language of Matlab 7.0.

\section{Results and Discussion}

The raw spectra at $25^{\circ} \mathrm{C}$, corrected for the background nitrate absorbance, are shown on Fig. 1. Thermal and chemical equilibria were confirmed in all solutions by repeated scans until the spectra remained unchanged. At first glance, the spectra resemble the absorbance of the pure uranyl ion. However, the same spectra normalized for the total uranyl ion concentration as shown in Fig. 2 provide evidence of complexation of the uranyl ion by nitrate, as manifested by an increase in the intensity and a small shift of the absorbance envelope in the 410 to $470 \mathrm{~nm}$ region towards longer wavelengths as the ligand concentration increases.

Increasing the temperature drastically diminishes the fine structure features as shown on the Fig. 3 and gives rise to a further increase of the uranyl ion complexation with nitrate. To quantify these effects, we first have to construct a chemical model for the reactions taking place in this system. The first step is to determine the number of absorbing species. This is done by analyzing the Factor Indication Function as mentioned in the previous section. The inverse IND function applied to the spectra of the solutions in the visible wavelength region ( 360 to $500 \mathrm{~nm}$ ) shows a sharp maximum at $k=2$ species at all studied temperatures (Fig. 4). This strongly suggests the presence of only two absorbing species, which can be ascribed to $\mathrm{UO}_{2}^{2+}$ and the first complex $\mathrm{UO}_{2} \mathrm{NO}_{3}^{+}$(also confirmed by the Raman study of Brooker [9]) the formation of which is defined by Eq. 8,

$$
\mathrm{UO}_{2}^{2+}+\mathrm{NO}_{3}^{-} \rightleftarrows \mathrm{UO}_{2} \mathrm{NO}_{3}^{+}
$$


Fig. 1 Background corrected spectra at $25^{\circ} \mathrm{C}$ for a series of uranyl nitrate solutions with nitrate concentrations ranging from $0.037 \mathrm{~mol} \cdot \mathrm{kg}^{-1}$ (solution a) to $3.12 \mathrm{~mol} \cdot \mathrm{kg}^{-1}$ (solution $\mathrm{m}$ )

Fig. 2 Spectra $\left(25^{\circ} \mathrm{C}\right)$ normalized to a constant $\mathrm{UO}_{2}^{2+}$ concentration of $0.007 \mathrm{~mol} \cdot \mathrm{kg}^{-1}$ for a series of solutions having nitrate concentrations ranging from 0.03 to $3.12 \mathrm{~mol} \cdot \mathrm{kg}^{-1}$

Fig. 3 Temperature dependence of absorption spectra having a uranyl concentration of 0.0088 $\mathrm{mol} \cdot \mathrm{kg}^{-1}$ and nitrate concentration of $0.483 \mathrm{~mol} \cdot \mathrm{kg}^{-1}$
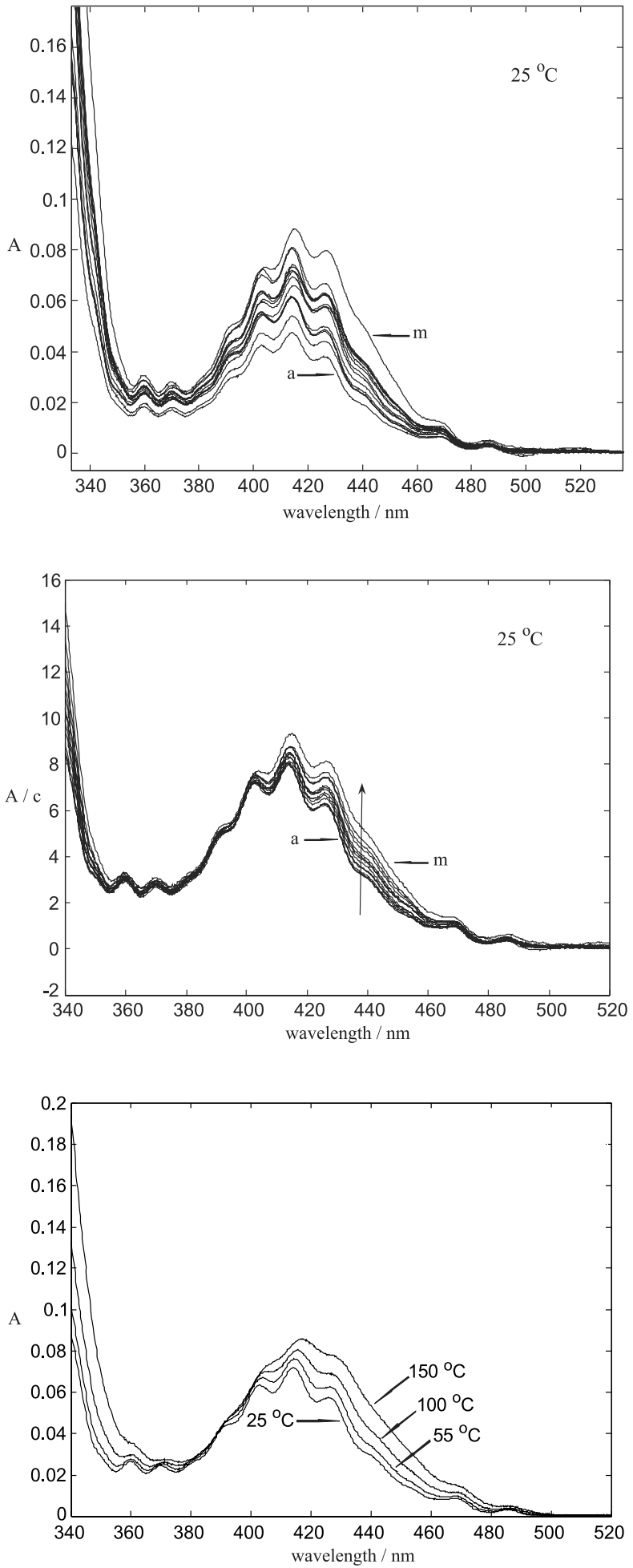
Fig. 4 The inverse IND function applied to the spectra demonstrates two absorbing species in the system

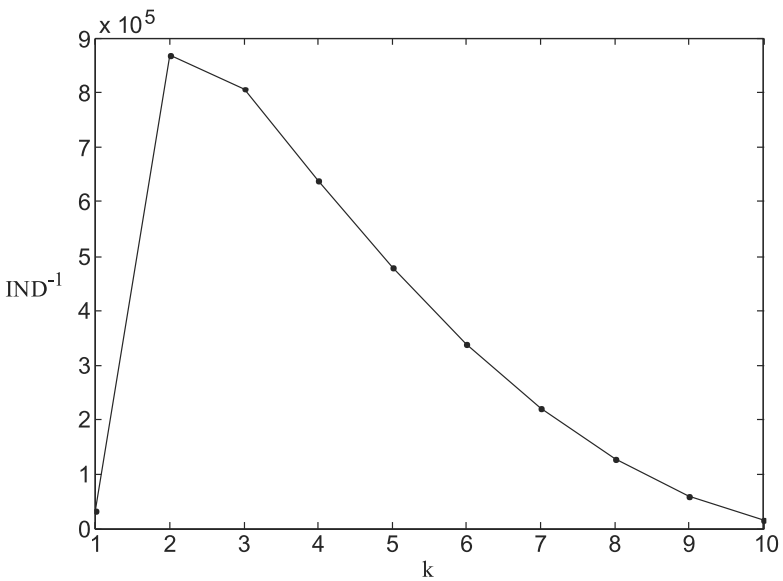

Now that the number and nature of the absorbing species are defined, the relevant mass action and mass balance equations may be solved in order to obtain the equilibrium constants. In this case, the following system of equations needs to be solved:

$$
\begin{gathered}
\beta_{1}=\frac{M_{\mathrm{UO}_{2} \mathrm{NO}_{3}^{+}} \gamma_{\mathrm{UO}_{2} \mathrm{NO}_{3}^{+}}}{M_{\mathrm{UO}_{2}^{2+}} M_{\mathrm{NO}_{3}^{-}} \gamma_{\mathrm{UO}_{2}^{2+}} \gamma_{\mathrm{NO}_{3}^{-}}} \\
M_{\mathrm{UO}_{2}}^{\text {total }}=M_{\mathrm{UO}_{2}^{2+}}+M_{\mathrm{UO}_{2} \mathrm{NO}_{3}^{+}} \\
M_{\mathrm{NO}_{3}}^{\text {total }}=M_{\mathrm{NO}_{3}^{-}}+M_{\mathrm{UO}_{2} \mathrm{NO}_{3}^{+}}
\end{gathered}
$$

where $\beta_{1}$ is the thermodynamic equilibrium constant for the reaction $8, \gamma_{\mathrm{i}}$ is the activity coefficient for the species $i$ and $M_{\mathrm{i}}$ is molarity of this species in solution. Activity coefficients of the individual ions were assumed to have the following form according to the Bronsted-Guggenheim-Scatchard approach [17-19]

$$
\log _{10} \gamma_{i}=-z_{i}^{2} D+\sum_{k} \psi(i, k) I
$$

where $D$ is the Debye-Hückel term:

$$
D=\frac{\mathrm{A} \sqrt{I}}{1+\mathrm{B} \stackrel{\circ}{ } \sqrt{I}} .
$$

$\mathrm{A}$ and $\mathrm{B}$ are temperature dependent constants, $z_{i}$ is the ion charge, $I$ is ionic strength, $\stackrel{a}{\text { is }}$ the effective diameter of the hydrated ion and $\psi(i, k)$ is the ion interaction parameter between ions $i$ and $k$. For this study, the term B $a ̊$ in the denominator of the Debye-Hückel term has been assigned a value of 1.5 as proposed by Scatchard [18]. Substituting Eq. 12 into Eq. 9 and combining the ion interaction coefficients, we obtain after minor rearrangement:

$$
\log _{10}\left(\frac{M_{\mathrm{UO}_{2} \mathrm{NO}_{3}^{+}}}{M_{\mathrm{UO}_{2}^{2+}} M_{\mathrm{NO}_{3}^{-}}}\right)+4 D=\log _{10} \beta_{1}+b I
$$


Table 2 The thermodynamic equilibrium formation constant for the reaction 8 at 1 bar for 25 to $70^{\circ} \mathrm{C}$ and at 4 bar for the 100 to $150^{\circ} \mathrm{C}$ temperature range; $b$ is overall Debye-Hückel interaction parameter defined in Eq. 14; and $Q$ is the apparent equilibrium constant

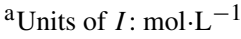

Fig. 5 van't Hoff plot of the experimental formation constants

\begin{tabular}{rrlll}
\hline$t /{ }^{\circ} \mathrm{C}$ & \multicolumn{1}{l}{$\log _{10} \beta_{1}$} & $b$ & $Q$ at $I=1^{\mathrm{a}}$ & $Q$ at $I=3^{\mathrm{a}}$ \\
\hline 25 & $-0.19 \pm 0.02$ & $0.05 \pm 0.01$ & 0.11 & 0.09 \\
40 & $-0.02 \pm 0.02$ & $0.09 \pm 0.02$ & 0.17 & 0.17 \\
55 & $0.16 \pm 0.03$ & $0.12 \pm 0.03$ & 0.26 & 0.30 \\
70 & $0.26 \pm 0.04$ & $0.17 \pm 0.03$ & 0.34 & 0.49 \\
100 & $0.49 \pm 0.04$ & $0.20 \pm 0.04$ & 0.53 & 0.85 \\
150 & $0.78 \pm 0.04$ & $0.24 \pm 0.04$ & 0.81 & 1.47
\end{tabular}

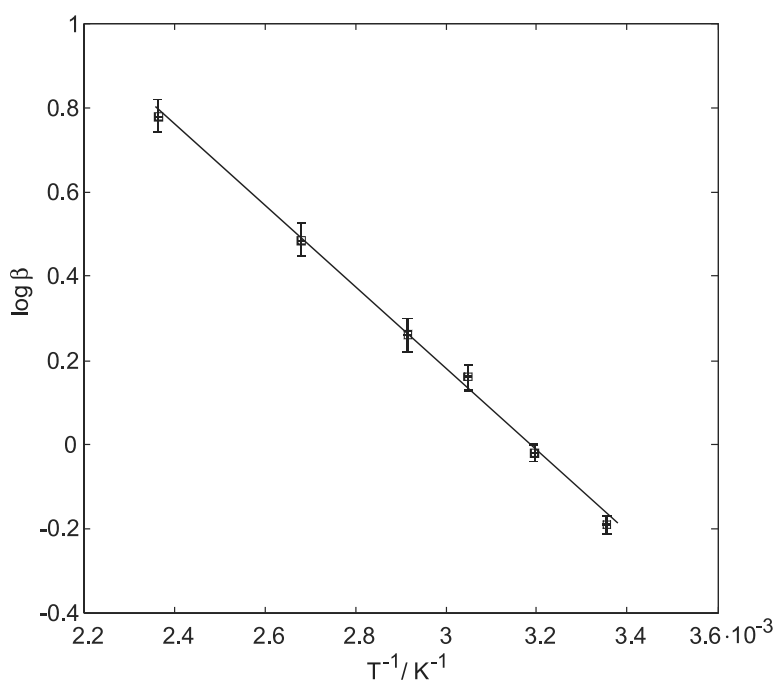

where the single parameter $b$ accounts for the concentration dependence of the apparent equilibrium constant, $Q=\frac{M_{\mathrm{UO}_{2} \mathrm{NO}_{3}^{+}}}{M_{\mathrm{UO}_{2}^{2+}} M_{\mathrm{NO}_{3}^{-}}}$. Considering $\beta_{1}$ and $b$ as being two independent variables, we can simultaneously solve Eqs. 14, 10 and 11 for the molar concentration of all species in solution. Molal to molar concentration scale conversion was based on the density of aqueous solutions of nitric acid and uranyl nitrate [20, 21]. At temperatures greater than $80^{\circ} \mathrm{C}$, the densities of nitric acid solutions were calculated from the relation given by Granzhan and Laktionova [20], which gives densities very similar to those reported by Patterson and Woolley [23] up to $95^{\circ} \mathrm{C}$ at $p=0.35 \mathrm{MPa}$. After that is done, it is possible to construct the objective function and find the minimum as described in the previous section. The results of the calculations are summarized in Table 2 and shown as a van't Hoff plot in Fig. 5.

The molar absorptivities of the $\mathrm{UO}_{2}^{2+}$ and $\mathrm{UO}_{2} \mathrm{NO}_{3}^{+}$are shown in Figs. 6 and 7, respectively. Increasing the temperature causes a pronounced increase of intensity and fine structure smoothing for both species $\mathrm{UO}_{2}^{2+}$ and $\mathrm{UO}_{2} \mathrm{NO}_{3}^{+}$. The contribution of the two absorbing species to the total solution absorbance at two arbitrary chosen concentrations are shown on Fig. 8 at 25 and $150^{\circ} \mathrm{C}$. Intermediate spectra were omitted for the sake of clarity. The absorption intensities are typical for spin allowed but Laporte forbidden electronic transitions. The formation of the asymmetric $\mathrm{UO}_{2} \mathrm{NO}_{3}^{+}$complex results in a partially Laporte 
Fig. 6 Molar absorptivity of the $\mathrm{UO}_{2}^{2+}$ ion in the temperature range 25 to $150^{\circ} \mathrm{C}$
Fig. 7 Molar absorptivity of the $\mathrm{UO}_{2} \mathrm{NO}_{3}^{+}$in the temperature range $25^{5}$ to $150{ }^{\circ} \mathrm{C}$
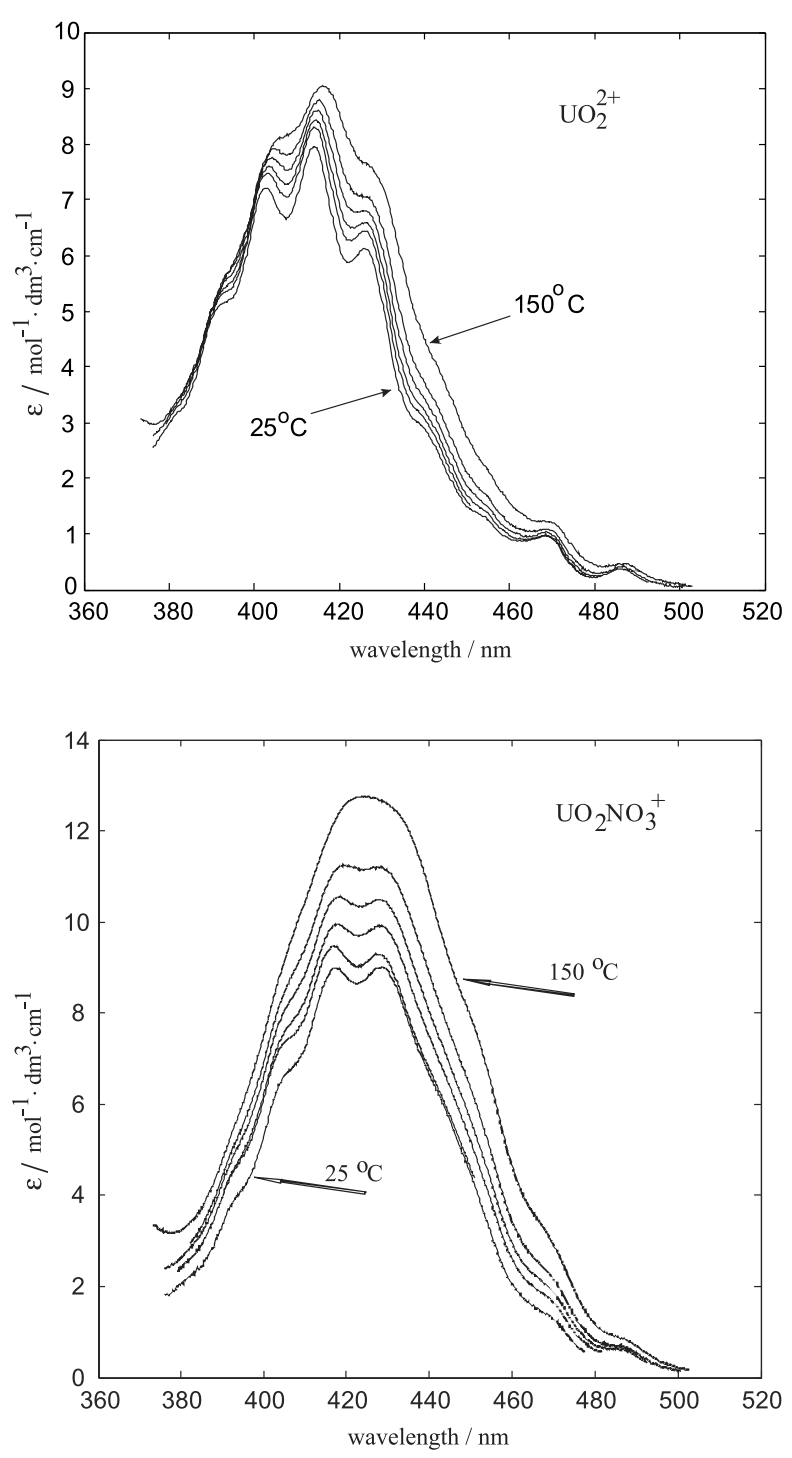

allowed transition due to vibronic coupling, and hence results in an increase of the transition intensity.

Finally, the enthalpy and entropy of the complex formation reaction were extracted from the temperature dependence of the equilibrium constants by fitting the equilibrium constants by the following expression,

$$
-\log _{10} \beta=\frac{A}{T}+B
$$

where $A, B$ are the coefficients of the fit and $T$ is the temperature in K. From Eq. 15, $\Delta H_{298}$ and $\Delta S_{298}$ for the complex formation reaction can be easily obtained through

$$
\Delta H_{298}=2.303 R A
$$



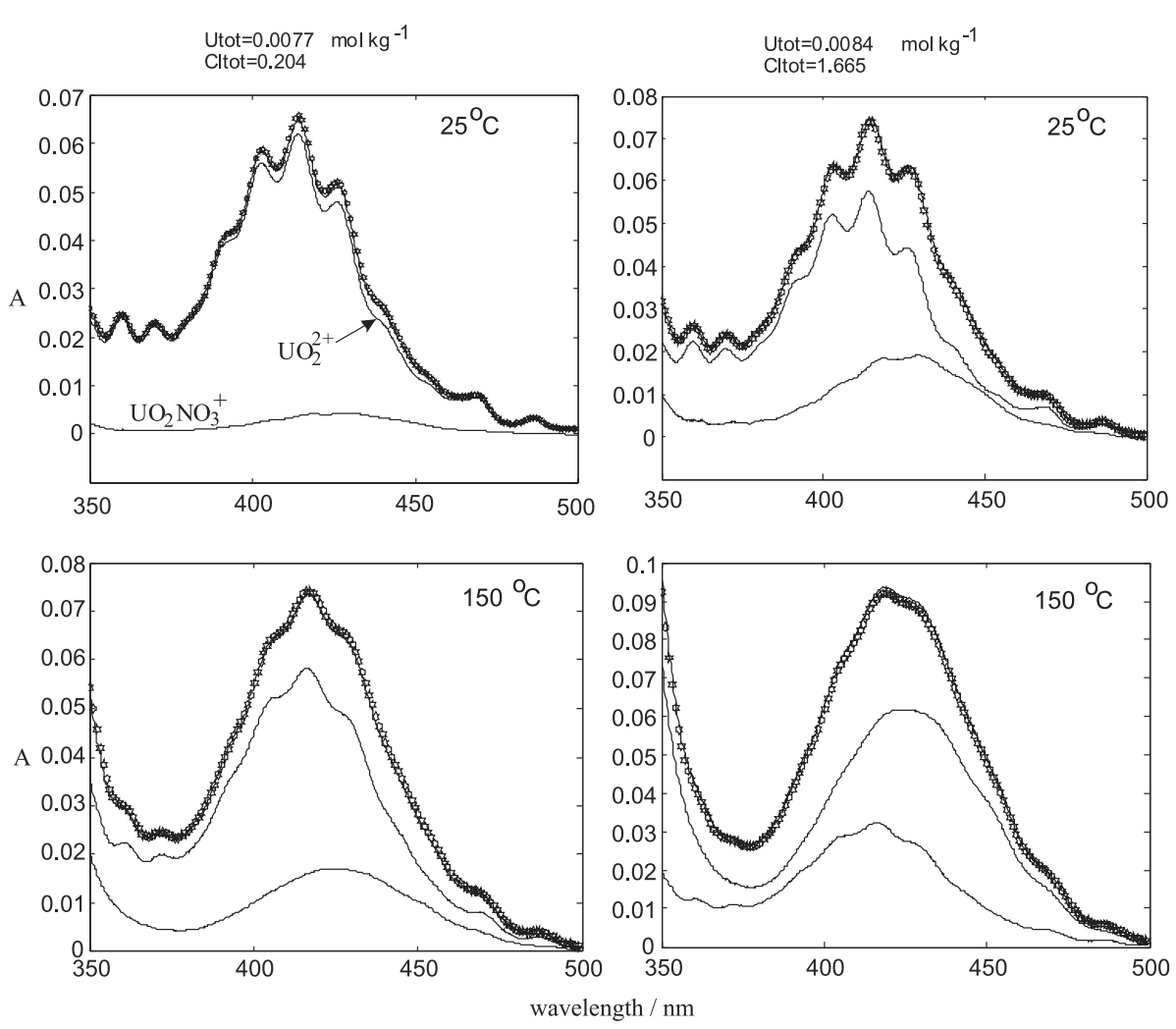

Fig. 8 The contribution of the two absorbing species to the total solution absorbance at 25 and $150^{\circ} \mathrm{C}$

$$
\Delta S_{298}=-2.303 R B
$$

where $R$ is the gas constant. Numerical values for $A$ and $B$ are 969.56 and -3.083 , respectively, which corresponds to the values $\Delta_{\mathrm{r}} H_{298}=18.5 \mathrm{~kJ} \cdot \mathrm{mol}^{-1}$ and $\Delta_{\mathrm{r}} S_{298}=59$ $\mathrm{J} \cdot \mathrm{mol}^{-1} \cdot \mathrm{K}^{-1}$ at $I=0$. Two other studies have reported equilibrium constants for the mononitratouranyl ion obtained as a function of temperature (over the restricted temperature range) and derived enthalpies and entropies for reaction 8. Marcantonatos et al. [7] reported $\Delta_{\mathrm{r}} H_{298}(I=0)=3.1 \mathrm{~kJ} \cdot \mathrm{mol}^{-1}$ and $\Delta_{\mathrm{r}} S_{298}=41 \mathrm{~J} \cdot \mathrm{mol}^{-1} \cdot \mathrm{K}^{-1}$ and Day and Powers [3] reported $\Delta_{\mathrm{r}} H_{298}\left(I=2 \mathrm{~mol} \cdot \mathrm{L}^{-1}\right)=-14 \mathrm{~kJ} \cdot \mathrm{mol}^{-1}$ and $\Delta_{\mathrm{r}} S_{298}=-62 \mathrm{~J} \cdot \mathrm{mol}^{-1} \cdot \mathrm{K}^{-1}$. However, the thermodynamic data reported from both these studies are considered to be no more than approximate given the notorious unreliability of the van't Hoff isochore approach in deriving enthalpies from equilibrium constant data that extend over a very limited temperature range of only $30 \mathrm{~K}$. The complex formation reaction is endothermic and entropy driven and is similar to those of inner-sphere complexes, which is also confirmed by the Raman study of Brooker et al. [9], where the band $1304 \mathrm{~cm}^{-1}$ was associated with monodentate nitrate bonded to the uranyl ion. 


\section{References}

1. Ahrland, S.: On the complex chemistry of the uranyl ion. VI. The complexity of uranyl chloride, bromide and nitrate. Acta Chem. Scand. 5, 1271-1282 (1951)

2. Betts, R.H., Michels, R.K.: Ionic association in the aqueous solutions of uranyl sulphate and uranyl nitrate. J. Chem. Soc. S286-S294 (1949)

3. Day, R.A., Powers, R.M.: Extraction of uranyl ion from some aqueous salt solutions with 2-thenoyltrifluoroacetone. J. Am. Chem. Soc. 76, 3895-3897 (1954)

4. Banerjee, D., Tripathi, K.K.: Association of uranium(VI) with anions in aqueous perchloric acid medium. J. Inorg. Nucl. Chem. 18, 199-206 (1961)

5. Ohashi, H., Morozumi, T.: Electrometric determination of stability constants of uranyl-chloride and uranyl-nitrate complexes with Cl-stat. Nippon Genshiryuoku Gakkaishi 9, 200-201 (1967)

6. Lahr, V.H., Knoch, W.: Bestimmung von Stabilitätskonstanten einiger Aktinidenkomplexe. II. Nitrat- und Chloridkomplexe von Uran, Neptunium, Plutonium und Americium. Radiochim. Acta 13, 1-5 (1970)

7. Marcantonatos, M.D., Deschaux, M., Celardin, F.: Ground- and excited state interaction between aquauranyl(VI) and nitrate. Chem. Phys. Lett. 69, 144-150 (1980)

8. Pushlenkov, M.F., Nikitina, G.P., Voden, V.G.: Formation of uranyl nitrate complexes with organophosphorous compounds. Radiochima 2, 215-221 (1960)

9. Brooker, M.H., Huang, C.-H., Sylwesrovicz, J.: Raman spectroscopic studies of aqueous uranyl nitrate and perchlorate systems. J. Inorg. Nucl. Chem. 42, 1431-1440 (1980)

10. Vogel, A.I., Bassett, J.: Vogel's Textbook of Quantitative Inorganic Analysis: Including Elementary Instrumental Analysis, 5th edn. Longman, Essex (1989)

11. Golub, G.H., Reinsch, C.: Singular value decomposition and least squares solutions. Numer. Math. 14, 403-420 (1970)

12. Wall, M.E., Rechtsteiner, A., Rocha, L.M.: Singular value decomposition and principal component analysis. In: Berrar, D.P., Dubitzky, W., Granzow, M. (eds.) A Practical Approach to Microarray Data Analysis, pp. 91-109. Kluwer, Norwell (2003)

13. Malinowski, E.R.: Determination of the number of factors and the experimental error in a data matrix. Anal. Chem. 49, 612-617 (1977)

14. Meloun, M., Čapek, J., Mikšik, P., Brereton, R.G.: Critical comparison of methods predicting the number of components in spectroscopic data. Anal. Chim. Acta 423, 51-68 (2000)

15. Bevington, P.R., Robinson, K.: Data Reduction and Error Analysis for the Physical Sciences, 2nd edn. McGraw-Hill, New York (1992)

16. Marquardt, D.W.: An algorithm for least-squares estimation of nonlinear parameters. J. Soc. Ind. Appl. Math. 11, 431-441 (1963)

17. Brønsted, J.M.: Studies of solubility. IV. The principle of specific interactions of ions. J. Am. Chem. Soc. 44, 877-898 (1922)

18. Scatchard, G.: Equilibrium in Solutions. Surface and Colloid Chemistry. Harvard University Press, Cambridge (1976)

19. Guggenheim, E.A.: Applications of Statistical Mechanics. Clarendon Press, Oxford (1966)

20. Granzhan, V.A., Laktionova, S.K.: Density, viscosity, and surface tension of aqueous solutions of nitric acid. Zh. Fiz. Khim. 49, 2461-2464 (1975)

21. Hovey, J.K.: Thermodynamics of Aqueous Solutions. Ph.D. Thesis, University of Alberta, Canada (1988)

22. Guorong, M., Liufang, Z., Chengfa, Z.: Investigation of the redox potential $\mathrm{UO}_{2}^{2+} / \mathrm{U}^{4+}$ and the complex formation between $\mathrm{U}^{4+}$ and $\mathrm{NO}_{3}^{-}$in nitric acid. Radiochim. Acta 38, 145-147 (1985)

23. Patterson, B.A., Woolley, E.M.: Thermodynamics of ionization of water at temperatures $278.15 \leq$ $T / \mathrm{K} \leq 393.15$ and at the pressure $p=0.35 \mathrm{MPa}$ : Apparent molar volumes and apparent molar heat capacities of aqueous solutions of potassium and sodium nitrates and nitric acid. J. Chem. Thermodyn. 34, 535-556 (2002) 